\title{
EXPLORANDO EL ORIGEN DE NUESTROS ANCESTROS: EL NACIMIENTO DEL PUEBLO NASA: LA HISTORIA DE UN GENOCIDIO*
}

\author{
Exploring the origin of our ancestors: the birth of the Nasa people: \\ the history of a genocide
}

Adriana Carolina Castro Bermúdez**

Román Francisco Téllez Navarro***

Recepción: 26 de abril de 2017. Aceptación: 20 de noviembre de 2017.

DOI: http://dx.doi.org/10.21017/Rev.Repub.2018.v24.a46

\section{RESUMEN}

En el presente artículo se describe cómo a partir de la llegada de los españoles al continente americano se perdieron todas las prácticas judiciales y jurisdiccionales que existían en el territorio descubierto. El ánimo expansionista y comercial hizo que los españoles desconocieran a los nativos como personas y mostraran poco interés en conocer su cultura, tradición y prácticas ancestrales, su cosmovisión y su propia historia. La conformación de los órganos judiciales indianos, anteriores a la llegada de los ibéricos, la forma de administración de justicia y la manera de dirimir los conflictos son desconocidas en nuestro tiempo, ya que las entidades impuestas por la monarquía española no solo contribuyeron al genocidio indígena de América del Sur,

* El presente artículo hace parte del proyecto de investigación aplicada, denominado «La jurisdicción indígena en la comunidad nasa: la resolución de conflictos en aplicación de la cosmovisión, las tradiciones y las costumbres ancestrales». Código del proyecto: 85772. Aprobado por la Institución Universitaria Politécnico Grancolombiano.

** Abogada de la Universidad Santo Tomás de Aquino. Especialista en Derecho Administrativo de la misma Universidad. Especialista en Derecho Constitucional de la Universidad de Salamanca. Especialista en Contratación Estatal de la Universidad Externado de Colombia. Candidata a Magíster en Derecho Público de la Universidad de Universität de Konstanz, en convenio con la Universidad Santo Tomás de Aquino. Docente del área de Derecho Público de la Institución Universitaria Politécnico Grancolombiano. Investigadora principal. Correo electrónico: accastrobe@ poligran.edu.co

*** Abogado de la Universidad Libre de Colombia. Especialista en Derecho Constitucional de la misma Universidad. Magíster en Derecho Procesal Penal de la Universidad Militar Nueva Granada. Docente del área de Derecho Público de la Institución Universitaria Politécnico Grancolombiano. Docente del área de Derecho Público de la Universidad Militar Nueva Granada. Investigador principal. Correo electrónico: rtellezn@poligran. edu.co; roman.tellez@unimilitar.edu.co 
sino a sepultar en el olvido la forma como estos pueblos resolvían sus diferencias. La pérdida de la figura del cacique como máxima autoridad terrenal y espiritual, así como la lucha de los pueblos aborígenes, en especial el pueblo nasa, en la búsqueda de su autodeterminación y autonomía, son claros ejemplos de este genocidio jurídico.

Finalmente, el producto de las constantes luchas sociales abanderadas por algunos pueblos indígenas se materializó en la Constitución de 1991, norma que bajo el amparo de algunos tratados internacionales y las interpretaciones de la Corte Constitucional, y en especial las decisiones adoptadas por la primera Corte, da relevancia a la justicia indígena basada en la idea de autonomía, la autodeterminación y el respeto por su cosmovisión. De esta manera se inicia el proceso de reivindicación de la cultura de los pueblos ancestrales, a partir de considerar la justicia indígena como una forma de justicia especial.

Palabras clave: Conquista de América, pueblo nasa, autodeterminación de los pueblos, justicia indígena y derecho propio.

\section{ABSTRACT}

The present article pretends to show how from the arrival of the Spaniards to the American continent all the judicial and jurisdictional practices that existed in the discovered territory were lost, thanks to the ignorance of the natives as persons and the lack of interest for their ancestral practices, as well as his worldview and his own history. How the Indian judicial organs were integrated is unknown to the inhabitants of the American people since the entities created by the Spanish Monarchy not only contributed to the indigenous genocide of South America, but also to obliterate the way in which these peoples, resolved their conflicts The loss of the figure of the Cacique as the maximum earthly and spiritual authority, as well as the struggle of the aboriginal peoples, especially the Nasa peoples seeking their self-determination and autonomy, are clear examples of this legal genocide.

Finally, it is from the constant social struggles that materialized in the new Colombian superior rule, Constitution of 1991, norm that under the protection of some international treaties and the interpretations of the Constitutional Court, in particular the decisions adopted by the first Court, they give relevance to the indigenous justice based on the formula of autonomy, self-determination and respect for their worldview, thus initiating the process of vindication of the culture of the ancestral peoples.

Key words: Conquest of America, Nasa people, self-determination of peoples, Indigenous Justice and Right. 


\section{INTRODUCCIÓN}

Desde la llegada de los españoles al continente americano, la población indígena fue sometida a diferentes vejámenes. Estos sufrimientos fueron causados por los conquistadores y los criollos que solo utilizaron su ayuda en búsqueda de un provecho y beneficio personal, y actualmente por el desprecio de la población que ve a los pueblos indígenas como intrusos dentro de su propio territorio. La exclusión legal y social a la que han sido expuestos llega hasta la degradación del término "indio" que, en palabras de William Ospina, se utiliza para la designación de una persona carente de todo tipo de cultura.

El desconocimiento de las formas propias basadas en su cultura, tradición, historia y cosmovisión ha llevado a que los pueblos indígenas se cierren al mundo occidental, casi hasta estados de chovinismo, intentando mantener su sabiduría alejada de lo que ellos consideran intromisiones foráneas. Y razones fundadas tienen para proceder así, pues han tenido que soportar toda clase de ofensas por parte de muchos habitantes, que en algunos casos ven su forma de existencia como algo arcaico, exagerado, extravagante, insólito y posiblemente de otro mundo, convirtiendo así su cosmovisión en un mero atractivo turístico.

La imposición de una nueva cultura a sangre, fuego y religión hizo desaparecer un saber milenario, pues, aunque los pueblos indígenas ya llevaban varios siglos en el continente americano, la pretensión de los españoles no era el intercambio cultural sino, por el contrario, imponer bajo el auspicio de la fe cristiana, una nueva forma de ver la vida y de vivir la cultura; por ello, todas estas experiencias, costumbres e historia son en buena parte desconocidas y olvidadas.

El padecimiento de los pueblos indígenas hasta los días actuales es inconmensurable; «han llegado al siglo XXI con secuelas de terror en sus comunidades, violencias de todos los tipos y todos los bandos que han generado dolor e indignación contra el actuar aberrante de los actores armados en sus territorios $^{1} \gg($ Korsbaek, 2009, p. 382).

Por otra parte, la desaparición del cacicazgo como figura de autoridad y la aparición del resguardo como imposición institucional española marcaron uno

1 En el marco del concepto de territorio, es importante hacer referencia en el derecho constitucional a la propiedad comunal de los grupos ancestros, lo cual es reflejo del papel del Estado Social de Derecho colombiano (Castro, 2018). 
de los golpes más potentes al sistema de gobierno indígena, y no bastaron las luchas sociales y los reclamos desde el período de la conquista, ni tampoco las excusas solicitadas por la iglesia católica para remediar el daño causado.

Así mismo, la segregación a la que fueron sometidos los indígenas es notable; el resguardo o tierras comunitarias constituye un ejemplo clásico de esta discriminación. La corona española, al no permitir a mulatos, negros o españoles residir en estos territorios, permitió el aislamiento de las comunidades indígenas durante mucho tiempo.

No obstante lo anterior, desde la promulgación de la Constitución de 1991, algunas normas internacionales, y en especial las interpretaciones dadas por la Corte Constitucional, las comunidades indígenas experimentan un pequeño bálsamo que les posibilita retomar sus casi olvidadas formas de aplicar justicia, iniciando la construcción de verdaderas comunidades autónomas e independientes; un ejemplo de ello es la conformación y el establecimiento de la guardia indígena ${ }^{2}$ en las comunidades de Tierradentro, Cauca, así como también el naciente sistema judicial que ya ha producido condenas ejemplares por su celeridad, forma de tipificar las faltas y juzgamiento en verdadera equidad y auténtica justicia.

A pesar de tener autonomía en la forma de administrar justicia, en virtud de que cada pueblo tiene sus propias formas y procedimientos, en los diferentes estudios e investigaciones realizados, como las de la historiadora Jacqueline Blanco Blanco, se encuentra homogeneidad en que todos lo hacen de manera libre, teniendo en cuenta su propia cosmovisión; mas no se evidencia, salvo en algunos casos y remedios como los fuetazos, el cepo o el calabozo, la operatividad de la justicia en casos particulares y tascendentales para las comunidades.

Es por lo anterior que en el presente artículo descriptivo se hace una reflexión sobre cómo el desconocimiento de los saberes ancestrales por parte de los españoles destruyó toda una teoría jurídica de administración de la justicia. El impacto es tal, que actualmente además del desconocimiento general para la población, los estudiantes de las facultades de derecho o de ciencia política del

2 De acuerdo con la CRIC, la guardia indígena es «un colectivo compuesto por niños mujeres y adultos», concebido "como organismo ancestral propio y como un instrumento de resistencia, unidad y autonomía en defensa del territorio y del plan de vida de las comunidades indígenas. No es una estructura policial, sino un mecanismo humanitario y de resistencia civil. Busca proteger y difundir su cultura ancestral y el ejercicio de derecho propio ». https://www.cric-colombia.org/portal/guardia-indigena/. 
país no tienen una cátedra de jurisdicción indígena, salvo las menciones esporádicas realizadas en las lecciones de Historia del Derecho y Derecho Constitucional Colombiano.

La metodología utilizada para la realización del presente artículo, corresponde, como lo señala Delgado (2010), «al método de investigación histórico analítico sintético» (p. 11), pues se parte del análisis e interpretación de escritores que han profundizado sobre los temas relacionados con la jurisdicción indígena, en especial los que rompen con el paradigma de lo tradicionalmente enseñado por los dómines de la historia. De igual manera, como fuentes primarias se utilizó bibliografía producto de investigación, libros o artículos publicados en revistas científicas, así como también textos producidos por las mismas comunidades indígenas, y del mismo modo, sentencias proferidas por la Corte Constitucional sobre la autonomía de los pueblos indígenas y tratados internacionales. Como fuentes secundarias se utilizaron las páginas web de las organizaciones indígenas. Para el análisis de la información se utilizó el método descriptivo y hermenéutico.

\section{NACIMIENTO DEL PUEBLO NASA}

Tradicionalmente se ha indicado y enseñado que el descubrimiento ${ }^{3}$ de América se dio en 1492, cuando Cristóbal Colón pisó el continente, territorio desconocido para aquel entonces en el mundo antiguo. Sin embargo, esta aseveración durante mucho tiempo ha sido puesta en duda, sobre todo por la más grande evidencia que se pueda presentar, radicada en que, cuando Cristóbal Colón llegó al continente fue recibido por personas.

Las diferentes teorías señalan que fueron los vikingos, los asiáticos y hasta los galeses quienes estuvieron en América, con anterioridad a Colón. Y esto fue posible, ya que, como lo sostiene Diamond (2007), hace 12.000 años, por Alaska ingresaron las primeras personas al continente. «El puente terrestre de Bering, durante los milenios de su existencia intermitente, habría llegado a tener una achura de 1.500 kilómetros (p. 54)» por donde posiblemente pudieron pasar las personas adaptadas al frío.

Desde el desembarco de los españoles en América los sistemas, mitos, leyendas y dogmas creados por las comunidades nativas fueron eliminados,

3 El término descubrimiento ha sido utilizado indiscriminadamente para señalar la llegada de los españoles al nuevo continente; sin embargo, este término encubre el concepto de dominación y destrucción de toda una cultura. 
pues según los españoles, estas prácticas eran idólatras, por lo que fueron borradas del imaginario colectivo. Sus sistemas políticos y judiciales fueron ignorados e incluso las creencias acerca de su origen fueron tildadas de paganas o impuras. Sin embargo, para algunos pueblos nativos, el Dios de la España no existe, existió o existirá, porque la creación del mundo en su cosmos es diferente a la establecida en su libro sagrado, como lo sostiene Galeano (2014):

La mujer y el hombre soñaban que Dios los estaba soñando. Dios los soñaba mientras cantaba y agitaba maracas, envuelto en humo de tabaco, y se sentía feliz y también estremecido por la duda y el misterio.

Los indios makiritare saben que Dios sueña con comida, fructifica y da de comer. Si Dios sueña con la vida nace y da nacimiento.

La mujer y el hombre soñaban que en el sueño de Dios aparecía un gran huevo brillante. Dentro del huevo, ellos cantaban y bailaban y armaban mucho alboroto, porque estaban locos de ganas de nacer. Soñaban que en el sueño de Dios la alegría era más fuerte que la duda y el misterio; y Dios, soñando, los creaba, y cantando decía: -Rompo este huevo y nace la mujer y nace el hombre. Y juntos vivirán y morirán. Pero nacerán nuevamente. Nacerán y volverán a morir y otra vez nacerán. Y nunca dejarán de nacer porque la muerte es mentira. (p. 3.)

En consonancia con lo anterior, para los americanos del altiplano cundiboyacense, la madre creadora de todo lo existente es Bachué, y la adoración al sol, al agua, al viento e incluso al fuego, símbolo que para los españoles representaba el infierno, eran verdaderas profesiones de fe, ya que en su sentir y pensar adorar estas deidades les aportaba algo bueno a sus comunidades. Estos dioses fueron creados bajo sus propias convicciones y culturas, sin imposición de credos diferentes a su propia vivencia, existir y cosmovisión. No obstante, en 1492 todas estas miradas y creencias se perdieron o fueron desaparecidas, como lo señala Galeano (2012):

...los nativos descubrieron que eran indios, descubrieron que vivían en América, descubrieron que estaban desnudos, descubrieron que existía el pecado, descubrieron que debían obediencia a un rey y a una reina de otro mundo y a un dios de otro cielo, y que este dios había inventado la culpa y el vestido y había mandado que fuera quemado vivo quien adorara al sol y a la luna y a la tierra y a la lluvia que la moja (p. 324).

Como es evidente, para la mayoría de los pueblos indígenas, la aparición en la tierra de los primeros pobladores tiene unas características especiales; para los 
nasa páez ${ }^{4}$ su nacimiento no tiene nada que ver con el desarrollo evolutivo de algunas especies, así como tampoco se refiere a los modelos creacionistas religiosos tratados de imponer a partir de la evangelización. Para este pueblo indígena su origen es netamente místico y mitológico.

Señala la cultura Nasa que el nacimiento de su pueblo se dio de la unión de la estrella con el agua. Dentro de sus creencias se indica que Uma (la tierra) y Tay (el sol) se unieron para crear los administradores y protectores de la tierra. Dos de estos protectores fueron y siguen siendo Até (la luna) y A (la estrella).

La estrella un día decide bajar a la tierra y al ver la tranquilidad, la paz y la transparencia del agua, tocó sutilmente con una de sus puntas la laguna sagrada y de allí nacieron los primeros habitantes del pueblo nasa. ${ }^{5}$

De acuerdo con su cultura, nacieron dos tipos de personas: los nasa que habitaron la superficie de la tierra y los tapanos que habitaron dentro de la tierra; estos últimos solo salían a la superficie en épocas de cosecha, para lo cual se abría una gran puerta. Se indica que los tapanos no podían comer sal ni ají así como tampoco consumir chicha, pues estos alimentos tenían energías negativas y contaminaban su comunidad.

Existía una norma sagrada que prohibía el ingreso de los nasa al interior de la tierra, porque impurificaban a la comunidad de los tapanos, pues los nasa consumían sal, ají y bebían chicha. Un día, un habitante nasa decide ingresar por la puerta sagrada, y esta se cerró para siempre; por lo que solo subsisten los que habitaron la superficie de la tierra.

Además de lo místico de su origen, el pueblo nasa páez fue un pueblo que se caracterizó por su lucha y resistencia contra las imposiciones de fe, tributarias, políticas y esclavizadoras que querían arrebatarles no solo su identidad sino

4 De acuerdo con el profesor Martínez (2015, p. 178), «se les conoce como Paeces, nombre dispuesto por los conquistadores españoles, tras la castellanización de pats en lengua nasa, que significa a la derecha del río». No obstante, las investigaciones y análisis realizados por los lingüistas nasa, en especial los del resguardo de Yaquivá, páez es una palabra compuesta donde «Pa» significa llegaron y «ez» piojo. Se puede pensar entonces que este vocablo no se dio por encontrarse a la derecha del río, sino un término peyorativo para designar la llegada de los españoles como la llegada de una plaga.

5 La laguna sagrada es la de Juan Tama, ubicada en el municipio de Belalcázar, en el departamento del Cauca. Deriva su nombre del líder indígena Juan Tama de la Estrella, quien combatió a los españoles en el siglo XVIII. De acuerdo con la mitología, este líder junto con su compañera, regresaron a la laguna, lugar donde habían nacido. Hoy en día esta laguna es un sitio sagrado para los miembros de la comunidad nasa. 
«su lengua y su cultura» (Bonilla, 1982). Por eso, su lucha en muchas ocasiones fue violenta. Inicialmente la oposición al opresor se dio por pequeñas comunidades, pero esta amenaza conllevó a que los pueblos indígenas, que desde otrora tenían pleitos entre sí, se unieran en contra del invasor, formando verdaderos ejércitos para mitigar los embates de los hasta ahora desconocidos caballos y armas que lanzaban fuego desde sus entrañas.

La mejor muestra del éxito de esta política de los indígenas caucanos fue el resultado de esta gran guerra. Todos hemos oído la historia de cómo la Gaitana y el cacique Pigoanza desarrollaron toda una campaña que les permitió reunir en 1538 más de 7.000 paeces, 6.000 yalcones y 7.000 pijaos. (Bonilla, 1982, p. 7)

A pesar de su constante resistencia, poco a poco el ejército nativo fue menguando por el poderío militar de los españoles. Las alianzas efectuadas entre españoles y algunos pueblos aborígenes que traicionaron a su pueblo y las enfermedades fueron estragando y debilitando la fuerza bélica rebelde. Como lo señala Melo (2017):

La catástrofe de la población tuvo varias causas: la muerte violenta de los varones indígenas, y a veces de mujeres y niños, en batallas o actos de retaliación; el hambre y la falta de alimentos por la «guerra de tierra sagrada»... Pero fueron las enfermedades y epidemias traídas por los europeos o por los esclavos africanos las que produjeron más muertes. (p. 53)

No obstante lo anterior, su lucha no decayó, destacándose diferentes conflictos que hasta el presente siguen conformando una serie de pugnas, no solo bélicas sino resistentes para lograr el reconocimiento de su cultura y costumbres, y en especial, el reconocimiento de su individualidad como pueblo.

Bajo estas perspectivas, toda la población indígena del continente americano, tanto en el norte como en el sur, fue poco a poco menguada, en su gran mayoría por las enfermedades traídas por los extranjeros y para las cuales los nativos no tenían defensas biológicas; también por las masacres perpetradas por los invasores y hasta por los trabajos inhumanos a los que fue sometida la población aborigen; finalmente, a través del mestizaje, también fue reducida la población indígena. De esta manera, no solo fueron extinguidas sus vidas sino también su cultura, profesión de fe, y hasta su forma natural de hacer justicia, desapareciendo por completo su visión cósmica. No obstante, los pueblos indígenas se resisten a desaparecer; hoy, gracias a la Constitución de 1991, se consagró la autodeterminación de los pueblos indígenas como un Derecho Fundamental. 


\section{FORMAS DE JUSTICIA ANTES DE 1492}

Cuando los españoles llegaron al nuevo continente no sabían que existían tantos pueblos indígenas y que entre ellos proliferaran diversas lenguas, culturas, tradiciones e incluso formas de administrar justicia; sin embargo, y en materia de autoridad, existía un común denominador en todos estos pueblos: el Cacique, como figura máxima de soberanía. Por ende, para ser Cacique se debían reunir ciertas cualidades como sabiduría, conocimiento, autoridad y reconocimiento, pues era el encargado de llevar las riendas de la comunidad, considerándose como verdadera figura de poder.

Es por lo anterior que la figura del cacique era asimilable a la de un rey o emperador, entre otras razones porque al morir este, era sucedido por su heredero más próximo, sus hermanos o parientes más cercanos; es decir, el sucesor debía provenir del mismo linaje; no obstante, también eran necesarias otras condiciones como: aptitudes de «buen gobierno», tales como la coordinación de actividades económicas, la generosidad y prodigalidad, la mediación en conflictos (internos y externos), la intermediación con las divinidades, la portación y exhibición de emblemas de prestigio, el liderazgo militar y la negociación con el poder imperial, las cuales fueron las claves que le otorgaron legitimidad a los kuraka prehispánicos... (Morrone, 2015, p. 209).

Fue evidente que este líder era la figura más importante dentro de la organización étnica; no obstante, para los españoles no era así, inicialmente porque desconocieron su poder como autoridad, excluyendo su profesión de fe, su organización social y cultural, al igual que las formas propias de hacer justicia. Para los españoles era difícil entender cómo operaba la población indígena; así lo señala Martínez (2015) al indicar lo siguiente: «Los conquistadores se encontraron frente a un sistema de gobierno el cual no sabían cómo identificar. Las unidades políticas eran los cacicazgos y estos a su vez estaban subdivididos en principales» (p.180).

Lo relevante en esta figura de autoridad es que su poder no derivaba del miedo o del sometimiento del pueblo hacia este, sino, por el contrario, era el respeto por la figura que él representaba en lo espiritual, en lo administrativo y demás, lo que hacía que la comunidad lo considerara como su líder; por lo anterior, el autor citado afirma que frente a las obligaciones de la comunidad sí existía una jerarquización, pero no una imposición:

...es decir el cacique está por encima de los demás miembros de la tribu, sin embargo, su poder no emana del miedo o la servidumbre, sino de la elección y unión de la población alrededor de un líder espiritual o guía comunal (Martínez, 2015, p. 183). 
Amén de lo anterior, el pueblo de nasa rompió con la figura del cacicazgo como una posibilidad para solo los hombres, pues fue una mujer, la cacica Gaitana, quien no solo fue relevante a la hora de administrar justicia, sino también al momento de ofrecer resistencia ante la invasión española, organizando un ejército para repeler los embates militares de los españoles ${ }^{6}$.

El proceso de colonización y de conquista española fue lento y costoso. Por eso, la Corona debió ceder la posibilidad de conquistas de territorios a los privados que, bajo ciertos premios, asimilables a las recompensas dadas a los mercenarios, tenían la potestad de someter a la población aborigen por los medios que fuera, por lo general violentos. Es así como se le otorga a Pedro de Añasco ${ }^{7}$ la posibilidad de colonizar los territorios de los nasa, para que en nombre de la reina subordinara a los pueblos indígenas ubicados en la zona de Tierradentro.

Es así que en el desarrollo de este proceso, cuenta la leyenda que es el asesinato del hijo de la cacica Gaitana lo que despertó en enfado del pueblo, pues este, al llegar al sitio donde se encontraba Pedro de Añasco, no reconoce como autoridad al español, y Añasco, con la clara intención de infundir miedo, lo asesina quemándolo vivo frente a su madre.

Por otra parte, y aunque los ejércitos aborígenes tuvieron varias batallas, el poderío militar español dominó y sometió por la fuerza a las poblaciones indígenas, a las que redujeron rápidamente, como lo señala Martínez (2015) citando a Raúl Arango: «...en el caso colombiano para 1492 había aproximadamente 10 millones de personas en todo el territorio, y para 1650 era menor o igual a 400.000 ». De igual forma, Raúl Arango también dice que para el caso nasa, estas cifras pudieron ser alarmantes (Arango, 1997, citado por Martínez, 2015, p. 189).

Por las razones mencionadas, al desaparecer la población indígena por el genocidio cometido, desapareció también su cultura y tradición, así como sus formas propias de hacer justicia, actuaciones completamente desconocidas para nuestro tiempo; más allá de algunos relatos, sentencias o antecedentes de cómo se administraba justicia, pues la escritura no era un atributo de la comunidades indígenas precolombinas, no existe evidencia alguna de las decisiones jurídicas y llegado el caso de existir antecedentes, posiblemente los conquistadores los destruyeron, teniendo en cuenta que estas prácticas rompían con su sistema

6 Como se evidencia para las comunidades indígenas, se puede pensar que no existía esa discriminación frente al género, que sí era expresada por los españoles.

7 Pedro Añasco fue comisionado por Sebastián de Belalcázar para fundar un territorio indígena alrededor de Timaná, Huila, en el año de 1538. http://www.banrepcultural. org/blaavirtual/biografias/gaitana.htm. 
y con su profesión de fe, eliminando de los anaqueles de la historia quizás la única teoría propia del derecho del continente americano: el derecho indígena.

\section{LA JUSTICIA LUEGO DE LA CONQUISTA}

En el segundo viaje realizado, Colón, por disposición real, se convirtió en almirante colonizador y gobernador de las nuevas tierras encontradas. Estas dignidades le dieron la posibilidad de legislar y administrar justicia en nombre de la Corona. La aplicación de estas potestades no dio espera. El mismo Colón, quien dentro de su afán por tener todo el oro posible y así cumplir unas de las promesas realizadas a la reina, ordenó la tarea de recolectar el oro a los habitantes de Haití, so pena de morir si no se lograba este cometido. El historiador norteamericano Howard Zinn (2005) describe de manera magistral esta condena:

En la provincia de Cicao, en Haití, donde él y sus hombres imaginaban la existencia de enormes yacimientos de oro, ordenaron que todos los mayores de catorce años recogieran cierta cantidad de oro cada tres meses. Cuando se la traían, les daban un colgante de cobre para que lo llevaran al cuello. A los indígenas que encontraban sin colgante de cobre, les cortaban las manos y se desangraban hasta la muerte. (p. 8 y 9)

Como se evidencia, desde el ámbito netamente comercial se crearon reglas o reguladores sociales que estaban enfocados solo en conseguir oro, desconociendo al otro como persona y como ser merecedor de respeto, excluyendo además las reglas propias con las cuales los nativos se administraban como sociedad. Los antiguos habitantes del continente «descubierto» se rehusaron constantemente a realizar esta labor de recolección del oro, siendo privados de la libertad bajo uno de los sistemas económicos más perversos inventados por la humanidad: la esclavitud. En pocas palabras, si el almirante Colón no podía remitir oro, enviaba esclavos.

Tres décadas después del descubrimiento, la monarquía española en 1524 crea el Consejo Supremo y Real de Indias, «como máximo organismo peninsular para el gobierno y la administración del nuevo mundo» (González, 1994, p. 52). Inicialmente fue integrado por el presidente «fray García de Loaisa y por los Consejeros: Luis Cabeza de Vaca, Diego Beltrán y Pero Mártir de Anglería» (Soberanes, p. 26); las máximas funciones estaban enmarcadas en lo legislativo, lo administrativo, lo militar y finalmente en lo judicial. Lo relevante de este Consejo es que impuso a su querer y parecer las normas que debían acoger los habitantes del continente americano, así como el procedimiento que se debía aplicar, en un idioma ajeno al de los habitantes de América. 
En la conformación de estos órganos, en especial el Consejo de Indias, nunca se tuvo en cuenta la cultura, la forma social indígena, pues estaba marcada la jerarquización del sistema de gobierno, como lo indica Bushnel (2007):

Como en la totalidad del imperio español, la estructura fue en principio, altamente centralizada. El territorio era gobernado por el Rey y sus consejeros desde España; el cuerpo consultivo más importante era el Consejo de Indias, cuyos miembros servían simultáneamente como tribunal administrativo, órgano legislativo y corte de apelaciones. (p. 32)

Si bien es cierto, este órgano se encargaba de administrar justicia, su principal actividad radicaba en las operaciones comerciales, es decir, en la forma de cómo los españoles podían lucrarse rápidamente con las riquezas, oro plata y demás, que extraían con mano de obra indígena y que prontamente transportaban a España. Por lo anterior, el concepto de dignidad como uno de los presupuestos de amor al prójimo no era aplicado a la población raizal del continente americano, ya que incluso los evangelizadores, salvo contadas excepciones como Fray Bartolomé de las Casas y Juan de Castellanos, ${ }^{8}$, vieron a los nativos americanos como animales carentes de alma y espiritualidad, siendo esto justificante para que este órgano también contribuyera en la destrucción de los saberes aborígenes sobre la justicia.

Otro elemento preponderante en la pérdida de la administración de justicia aborigen corresponde a la pretensión de los conquistadores para imponer su religión; para ello era necesario convertir, a como diera lugar, a los nativos a la fe cristiana, incluso encontrando justificaciones para tal fin como lo sostiene Estrada (1992): «Es injusto criticar a los evangelizadores por actitudes, comportamiento y valores que eran los de su tiempo, ya que representaban una cultura y una iglesia determinadas, y no podemos comprenderlos sin atender a su contexto histórico». (p. 7), pero también lo es que en este proceso se desconocieron muchos preceptos sobre los cuales se edificaron los pilares fundamentales de la cristiandad como el amor al prójimo; por ello, varios pontífices de la Iglesia Católica, como Juan Pablo II, Benedicto XVI, e incluso el Papa Francisco, han pedido perdón por lo ocurrido en la conquista.

Es importante resaltar que actualmente para los pueblos indígenas existe una estrecha relación entre la forma de administrar justicia y su espiritualidad; por ello, los juicios que se desarrollan en estas comunidades, aparte de aplicar los

8 Al respecto, el escritor Fernando Soto Aparicio escribió la novela biográfica llamada El sueño de la Anaconda, en donde se evidencia el sufrimiento de los indígenas y la lucha del religioso Juan de Castellanos por defender los derechos de estos. 
procedimientos y derecho propios, buscan en sus dioses, espíritus y demás conceptos ultraterrenales, la guía y la protección para que sus juicios tengan la dosis de justicia necesaria para que la armonía de su pueblo no se destruya.

Por lo anterior, al imponer una religión y al no respetar la propia, se rompió con esta conexión entre lo divino y lo humano, conexión preponderante y necesaria dentro de la cosmovisión de las comunidades indígenas. Es más, como lo señala Thomas Duve (2010), el derecho canónico siempre se impuso sobre el derecho indígena, ya que durante este proceso no se ordenó ningún sacerdote de procedencia indígena, teniendo en cuenta, y como lo señala el autor, citando a santo Tomás de Torquemada, que, aunque existieron indígenas convertidos y con grandes atributos para reproducir la fe cristiana, estos eran mejores obedeciendo que mandando.

Finalmente el Consejo de Indias termina su operación a comienzos del siglo XIX, después de haber despojado a los pueblos indígenas de sus riquezas, su cultura, su herencia y su historia, dejando al verdadero pueblo americano en la miseria y devastación, configurándose de esta manera, uno de los genocidios más grandes de la humanidad.

Por otra parte, y frente al proceso de independencia, se evidencia, como lo indica el profesor Jairo Gutiérrez Ramos (2010), que las comunidades indígenas se hicieron partícipes de las luchas en uno y otro bando, realista o patriotas, pero su actividad bélica se redujo a ser cargueros, proveedores y enfermeros, y en algunos casos soldados, en todo caso luchando por causas complemente ajenas a su existir.

La independencia no trajo a los pueblos indígenas la liberación que querían los criollos, pues como lo observa la historiadora Jacqueline Blanco (2008), «...la exclusión se presenta como una práctica social históricamente pareja a la conformación del Estado... al negarse a reconocer durante muchos años a los indígenas como sujetos de derechos... (p. 1)», apartándose por completo de la tendencia de un Estado cosmopolita que busca, como lo señalan Franco, Rengifo y Rojas (2018), «...garantizar la seguridad jurídica de los derechos individuales y colectivos, y establecer el principio de legalidad e igualdad más allá de la sociedad nacional ofreciendo garantías para hacer más eficaces los derechos humanos». (p. 116)

Por lo anterior, la lucha entablada por los pueblos indígenas por el reconocimiento como comunidad, la recuperación de sus tierras ancestrales, hasta el respeto por su propia forma de justicia, no cesa, ya que como lo señala la misma autora: "Pese al "control" del Estado, en este periodo se registraron algunas protestas sociales que, sin pretender mayores transformaciones 
estuvieron lideradas por indios, negros o mestizos, como el caso de la insurrección de los comuneros de El Socorro en 1781»(Blanco, 2005, p. 4); tal circunstancia no ha presentado modificación alguna y sigue constante hasta nuestros días.

\section{LA CONSTITUCIÓN DE 1991 Y LA JURISDICCIÓN INDÍGENA}

No es una novedad afirmar que los debates constitucionales en América Latina, caracterizados por la tensión entre neoliberalismo y derechos humanos, han implicado nuevos desafíos a la idea tradicional de Estado regulador (Sánchez, 2018). Es en este sentido que a finales de la década de los ochenta del siglo XX, Colombia vivió uno de los momentos más importantes en su historia constitucional. A partir del poder del constituyente primario, se transmutó la arcaica Constitución de 1886 por una de orden progresista, diversa e incluyente, bajo la fórmula de un estado social de derecho con fundamento en la dignidad humana, el reconocimiento de la diversidad y del pluralismo, entre otros aspectos.

La construcción dogmática de la Carta Magna se dio gracias a la pluralidad de personas que participaron en la elaboración de la misma; 70 miembros dentro de los cuales se encontraban integrantes de los partidos tradicionales, de los grupos desmovilizados, de las comunidades afrodescendientes e indígenas. Por parte de estas comunidades participaron el guambiano Lorenzo Muelas Hurtado y el embera chamí, Francisco Rojas Birry; por esto, para el profesor Quinche (2012), la Constitución de 1991

...es la más legítima de todas las constituciones que han sido expedidas en la historia de Colombia, pues en su formación y expedición participaron directamente el pueblo y todas las instituciones del Estado, alrededor de ocho momentos puntuales, materializados en el contexto previo, tres votaciones populares, dos decretos presidenciales de contenido legislativo y dos sentencias de la Corte Suprema de Justicia, en su calidad de órgano de cierre del sistema y de titular del control judicial de constitucionalidad de la época (p. 17).

Aunado a lo anterior, y de acuerdo con lo señalado por la historiadora Beatriz Londoño (2002), la influencia de estos líderes indígenas fue fundamental en los siguientes temas:

1. El ordenamiento territorial; 2. la apertura de espacios políticos y sociales de participación para los indígenas y los demás grupos étnicos, en especial la circunscripción especial indígena para el Senado 
y la circunscripción especial para grupos étnicos; 3 . el reconocimiento del carácter multiétnico y pluricultural de nuestro país y la garantía a derechos territoriales y culturales de los indígenas en la nueva constitución.

Dadas estas iniciativas, las comunidades indígenas cuentan con representación en el Congreso de la República, lo que les permite a las mismas contar con todo el respaldo legislativo para preservar sus tradiciones contra toda intervención foránea o ajena. Este reconocimiento se dio gracias a las incesantes luchas de las comunidades aborígenes a lo largo y ancho del mundo, consiguiendo entre otros logros, que la Organización Internacional del Trabajo se pronunciara sobre la protección de la autodeterminación de los pueblos indígenas con dos Convenios Internacionales, el número 107 en 1957 y el 169 en 1989, este último ratificado por Colombia el 7 de agosto de 1991 mediante la Ley 21, señalando en el artículo segundo que:

Los gobiernos deberán asumir la responsabilidad de desarrollar, con la participación de los pueblos interesados, una acción coordinada y sistemática con miras a proteger los derechos de esos pueblos y a garantizar el respeto de su integridad.

De igual manera, el Convenio en su artículo 8, numerales 1 y 2 , indica que al momento de aplicar justicia, se deberá reconocer su cultura, tradición y cosmovisión; en esencia, se les permite a las comunidades indígenas darse su propio régimen jurídico, siempre y cuando no vaya en contravía de los postulados de la Constitución Política.

Frente a los postulados constitucionales, se estableció como un Derecho Fundamental el reconocimiento y la protección «de la diversidad étnica y cultural de la nación colombiana» (artículo 7); de igual manera, en el artículo 10 fija lo siguiente: «Las lenguas y dialectos de los grupos étnicos son también oficiales en sus territorios». Finalmente se establece en el artículo 246, la libertad para que las comunidades indígenas puedan ejercer las funciones «jurisdiccionales dentro de su ámbito territorial, de conformidad con sus propias normas y procedimientos, siempre que no sean contrarios a la Constitución y leyes de la República».

Este derecho constitucional ha sido desarrollado por la Corte Constitucional mediante diferentes pronunciamientos frente a acciones de tutela, como los señalados en la Sentencia T-349 de 1996, mediante la cual se deja claro que, frente al conflicto de competencias entre la jurisdicción occidental y la indígena, para dirimir estas diferencias es necesario entender que, 
...el intérprete, al ponderar los intereses que pueden enfrentarse en un caso concreto al interés de la preservación de la diversidad étnica y cultural de la nación, atienda a la regla de la «maximización de las restricciones de la autonomía de las comunidades indígenas y, por lo tanto, de la minimización de las restricciones indispensables para salvaguardar intereses de superior jerarquía». ( Gaviria, 2002, p. 336).

Señala, entonces, el alto tribunal, que como regla general, es necesario preservar la cultura indígena bajo los presupuestos de su cosmovisión comunitaria y que estas restricciones solo pueden darse únicamente si se afectan intereses o derechos de mayor jerarquía o que la medida, si se debe tomar, sea la menos gravosa para su autonomía.

Como bien se observa, es necesario establecer una diferencia positiva frente a la jurisdicción indígena, pues esta trasciende los criterios del procedimiento y de la ley, ya que para las comunidades indígenas tiene más peso su cultura, surcada por sus propias visiones, metafísicas, la tradición, cultura y preservación de su armonía, que de la verdad procesal.

Teniendo en cuenta estos postulados, la Corte Constitucional desarrolló dos parámetros fundamentales para establecer la competencia de una u otra jurisdicción. Indica el alto tribunal que a la hora de saber quién debe impartir justicia, es necesario tener en cuenta dos parámetros objetivos: «las características del sujeto y el lugar donde ocurrieron los hechos» (Gaviria, 2002, p. 340). Lo anterior indica que es necesario, por una parte, establecer si quien comete una falta hace parte de alguna comunidad indígena, y por la otra, si la misma se cometió dentro de un resguardo indígena.

Bajo estos postulados, todos los pueblos indígenas colombianos tienen una estructura de gobierno parecida y regida por el respeto irrestricto a la jerarquía fundamentada en el sentir comunitario de las mismas. En este orden, cada resguardo está administrado bajo los siguientes parámetros: la Asamblea General como órgano máximo de la comunidad; un órgano de gobierno radicado en el Cabildo, con un cabildante líder denominado gobernador, quien es elegido para tal dignidad por la Asamblea General y finalmente unos comités que ayudan al cabildo con algunas tareas (dentro de estos está el comité de justicia).

Frente al sistema judicial, en el caso especial de la comunidad nasa, es necesario indicar que no se cuenta con un aparato judicial permanente; está en cabeza del cabildo, la actividad de investigación y sanción de las faltas cometidas; y frente a la forma y procedimiento, como lo señala el profesor Perafán (1995), está «regido por un sistema sincrético, que combina los patrones de comportamiento de la cultura páez, con las regulaciones propias del fuero indígena colombiano sobre resguardos indígenas» (pp. 49-50). 
El sistema judicial de la comunidad nasa concibe las afrentas a sus miembros o las transgresiones a sus normas de conducta como una falta contra la colectividad y no bajo la mirada de la individualidad. No obstante, también la espiritualidad tiene una gran importancia, pues a la hora de imponer los remedios ${ }^{9}$, como por ejemplo el fuete, es el cabildo y el médico tradicional quien señala si uno de los comuneros encargados de realizar esta actividad es apto para tal fin.

De igual manera, y con ocasión de casos que tengan relevancia social por su impacto en la comunidad y por la gravedad de la falta, es la Asamblea General la que impone los respectivos remedios, que previamente han sido propuestos por el comité judicial instaurado para el conocimiento del tema, el que a su vez es el órgano asesor del cabildo. En esa asamblea, muy similar al concepto de la democracia directa griega, amplía el ámbito de aplicación de la misma, a faltas que se constituyan en desarmonizaciones graves de la sociedad, incluyendo a todos los miembros de la comunidad, incluso a los niños, en la toma de sus decisiones ${ }^{10}$.

\section{CONCLUSIONES}

Se pueden considerar teorías propias del derecho, aquellas que han nacido producto del desarrollo social de las comunidades, es decir, del infinito acomodo de las relaciones de la comunidad. Se puede pensar, entonces, que también son teorías propias del derecho, aquellas que están inspiradas en la cultura, sin intervención de saberes o teorías extrañas, que por el contrario, proceden de la propia depuración social de la comunidad, tal como pudo haber sido el sistema jurídico indígena precolombino.

La carencia de formas de expresión escrita, impidió que las decisiones tomadas por parte de los pueblos aborígenes que habitaron el continente americano, en el marco de las formas de administrar justicia y con el fin de resolver

9 Para las comunidades indígenas colombianas el concepto de falta se encuentra ligado a lo colectivo, desarmonizando la comunidad, y por tanto es necesario aplicar un remedio para que se vuelva a la concordia. A través del fuete se purifica al comunero y puede considerarse, nuevamente, miembro de la comunidad.

10 En concordancia con lo dispuesto y atendiendo a la necesidad de protección a las comunidades indígenas, es importante resaltar que siempre que se hace referencia a los sujetos de derechos normalmente se asimila este con el concepto de persona, entendiendo a este como la única concepción que existe dentro de la categoría de sujetos de derechos sin que se incluyan otras concepciones tales como la de sujeto de relevancia jurídica, sujeto de especial protección, etc. (Herrera, 2018). 
todo tipo de conflicto, fueran conocidas en nuestra época. Únicamente se conoce la figura del cacique como referencia de autoridad, mas no se encuentran antecedentes de las decisiones que este tomaba frente al ejercicio de juez o árbitro.

Los españoles, en su proceso de conquista del continente americano, sumado al proceso de evangelización y la extracción de riquezas del continente, produjeron uno de los genocidios más grandes en la historia de la humanidad. Al desaparecer por completo pueblos ancestrales, también se perdieron sus saberes, creencias, mitos, leyendas, dogmas y finalmente sus formas de gobierno, disipándose también, la única forma del derecho propio en el continente americano.

La eliminación del cacicazgo como figura de autoridad, la imposición a sangre y fuego de la religión católica, la implementación del resguardo y la imposición de procedimiento jurídicos distintos a los ancestrales, terminaron sepultando el derecho propio que desde hacía varios siglos poseían y practicaban los pueblos indígenas.

Gracias a la expedición de la Constitución de 1991, en Colombia se materializa la posibilidad de autodeterminación de los pueblos indígenas, con la consagración de este derecho en el artículo séptimo, que reconoce la diversidad étnica, así como la posibilidad de gobernarse tomando como fuente su cultura, tradición y cosmovisión, permitiendo la creación de su propia jurisdicción, una jurisdicción especial.

La Constitución de 1991 y de manera muy especial las decisiones adoptadas por la Primera Corte Constitucional comienzan el camino de la reivindicación de los derechos de los pueblos indígenas, dando relevancia a la justicia indígena basada en la aplicación de la autonomía, la autodeterminación y el respeto por su cosmovisión.

Aunque la deuda con los pueblos ancestrales comienza a enmendarse, aún es extenso el camino por recorrer para recuperar ese derecho propio; por ello el proceso de consolidación como nación no estará completo hasta tanto se siga desconociendo su historia, su génesis que es la misma nuestra, nuestras raíces, nuestra identidad.

\section{REFERENCIAS}

Blanco J. (2005). Colombia multicultural. Historia del Derecho a la Inclusión. Revista Diálogo de Saberes. Universidad Libre de Colombia. 
Blanco J. (2008). La jurisdicción especial indígena, más allá del mandato constitucional. Universidad Libre de Colombia.

Bonilla V. (1982). Historia política de los paeces. Colombia Nuestra Ediciones.

Bushnel D. (2007). Colombia una nación a pesar de sí misma. Nuestra historia desde los tiempos precolombinos hasta hoy. Editorial Planeta.

Castro G. (2018). Una aproximación teórica a la obra de Arturo Valencia Zea, De la posesión y la función social de la propiedad: el gran problema jurídico del siglo $x x$ en Colombia, revisión histórico jurídica en Revista Via Inveniendi et Iudicandi, 13(1), enero-junio 2018, pp. 9-54. DOI: http:/ / dx.doi.org/10.15332/ s1909-0528.2018. 0001.01. Documento extraído el 2 de abril de 2018 de http:/ / revistas.usantotomas. edu.co/index.php/viei/article/view/4265/4042

Constitución Política de Colombia.

Corte Constitucional. Sentencia T-346 de 1996. Magistrado ponente, Carlos Gaviria Díaz.

Corte Constitucional. Sentencia T-881 de 2002. Magistrado ponente, Eduardo Montealegre Linett.

Delgado G. (2010). Conceptos y metodologia de la investigación histórica. Rev Cubana Salud Pública v.36 n.1 Ciudad de La Habana ene.-mar. 2010.

Diamond J. (2007). Armas, gérmenes y acero. Breve historia de la humanidad en los últimos 13.000 años. Random Hause Monadadori. Colombia.

Duve T. (2010). Esplendores y miserias de la evangelización en América. Antecedentes europeos y alteridad indígena. Derecho canónico y alteridad indígena: Los indios como neófitos. Walter de Gruyter GmbH \& Co. KG, Berlín/New York.

Estrada J. (1992). Las contradicciones en la evangelización de América. Análisis ético y teológico. Editorial Sal Terrae España.

Franco J. Rengifo A. Rojas L. (2018). Estado cosmopolita en América Latina. Universidad Santo Tomás. Revista IUSTA, n.o 48, enero-junio 2018, pp. 97-117.

Galeano E. (2012). Los hijos de los dias. Siglo Veintiuno Editores. Argentina.

Galeano E. (2014). Memorias del fuego I. Los nacimientos. Siglo Veintiuno Editores. Argentina.

González, P. (1994). Archivo General de Indias. Recuperado en: http:/ / institucional. us.es/revistas/universitaria/extra1994/art_4.pdf. 
Gaviria C. (2002). Sentencias. Herejías constitucionales. Fondo de Cultura Económica.

Gutiérrez J. (2010). Los indígenas en la independencia. Revista Credencial. Edición 247. Recuperado en: http://www.banrepcultural.org/node/86367.

Herrera M. La Gaitana. Recuperado en: http:/ / www.banrepcultural.org/blaavirtual/ biografias/gaitana.htm.

Herrera B. (2018). Derechos de los animales: la legislación nacional interna como barrera legal para el reconocimiento de la subjetividad jurídica animal. Revista Via Inveniendi et Iudicandi, 13(1), enero-junio 2018, pp. 55-93. DOI: http://dx.doi. org/10.15332/s1909-0528.2018.0001.02. Documento extraído el 1 de abril de 2018 de http:// revistas.usantotomas.edu.co/index.php/viei/article/view/4266/4043

Korsbaek Leif. Los peligros de la comunidad indígena y sus defensas. Revista Ra Ximhai.

Universidad Autónoma Indígena de México. Recuperado en: http://www.uaim. edu.mx/webraximhai/i/Ej-15articulosPDF/11 PELIGROS DE LA COMUNIDAD. pdf

Llano J., Rengifo R. y Rojas L. (2018). Estado Cosmopolita en América Latina. Revista IUSTA, 48, enero-julio. Universidad Santo Tomás.

Londoño B. (2002). La Constitución de 1991 y los indígenas. Revista Credencial. Edición 146. Recuperado en: http:/ / www.banrepcultural.org/blaavirtual/revistas/ credencial/febrero2002/laconstitucion

Morrone, Ariel J. (2015). Memoria en la sangre y en la tierra. Liderazgo, sucesión y territorialidad en el sur andino (corregimiento de Pacajes, 1570-1650). Indiana [en línea]. Disponible en: <http:/ / www.redalyc.org/articulo.oa?id=247043388010> ISSN 0342-8642.

Morner Magnus. Las comunidades de indígenas y la legislación segregacionista en el Nuevo Reino de Granada. Revista de la Universidad Nacional de Colombia. Recuperado en: https:// revistas.unal.edu.co/index.php/achsc/article/viewFile/29622/ 29860.

Martínez D. (2015). Educación, Identidad y Derechos como estrategias de los pueblos indígenas. II decenio de los pueblos indígenas (2005-2015). Más allá de la resistencia civil: Juan Tama y la cacica Gaitana en los antecedentes de la resistencia no violenta de los pueblos Nasa. Universidad Católica de Murcia, España.

Melo O. (2017). Historia mínima de Colombia. Turner Publicaciones.

OIT. Convenio nro. 169 del 7 de junio de 1989. 
Ospina W. (2013). Pa que se acabe la vaina. Editorial Planeta.

Perafán, C. (1995). Sistemas jurídicos paez, kogi, wayúu y tule. Instituto Colombiano de Cultura.

Quinche, F. (2012). Derecho Constitucional Colombiano: De la Carta de 1991 y sus reformas. Editorial Temis, Quinta Edición. Bogotá.

Sánchez R. (2018). La regulación de participación. El caso de la consulta previa en Colombia, Perú y Chile. Revista Via Inveniendi et Iudicandi, 14(1), pp. 95-118. DOI: http://dx.doi.org/10.15332/s1909-0528.2018.0001.03. Documento extraído el 2 de abril de 2018 de http:/ / revistas.usantotomas.edu.co/index.php/viei/article/ view $/ 4267 / 4044$

Soberanes J. (s. f.). El poder judicial federal en el siglo XIX. Recuperado en: https:/ / archivos.juridicas.unam.mx/www/bjv/libros/2/815/4.pdf.

Soto F. (2012). El sueño de la Anaconda. Editorial Educar.

Zinn, H. (2005). La otra historia de los Estados Unidos desde 1492 hasta el presente. 
